\title{
Unique Insights into Dispersion Distances Among Calling Males of Wahlberg's Epauletted Fruit Bat in Kruger National Park, South Africa
}

\author{
Rick A. Adams ${ }^{*}$ and Emily R. Snode
}

School of Biological Sciences, University of Northern Colorado, Greeley, CO 80639, USA

\begin{abstract}
In June 2009, we used a novel technique to quantify dispersion patterns among a large group of calling male Epomophorus wahlbergi congregated around five neighboring and synchronously fruiting sycamore fig trees (Ficus sycomorus) in Kruger National Park, South Africa by using the physics of sound attenuation over distance to monitor and map positions of calling males without disturbing their mating behavior. The lack of fruiting sycamore fig trees across the area concentrated males among five fruiting trees along a $10 \mathrm{~km}$ stretch of riverine corridor that paralleled the river road. We hypothesized that the patterns of dispersion among calling males would be clumped in relation to fruiting fig trees that attract foraging females. Results show that the distribution of calling perches were clumped $(\mathrm{R}=0.75)$ as opposed to randomly or equally dispersed. In addition, we found that a $2 \mathrm{~km}$ section of the corridor contained the majority of calling males and in this area calling males were more tightly clumped $(\mathrm{R}=0.58)$ than across the other $6 \mathrm{kms}$ of corridor. In addition, distances among calling males and their nearest neighbor were significantly less on average (25m) in the higherdensity area, than in the lower density areas $(315 \mathrm{~m})(\mathrm{P}<0.001)$. Although most males were near fruiting figs, they maintained a minimum dispersion and never were observed calling from the same tree. In addition, some males appeared dominant over others and consistently positioned themselves closest to ripe fig trees where females were foraging. Our data give previously unobserved insights into how male Wahlberg's epauletted fruit bats position their calling roosts in relation to one another and fruiting fig trees under conditions of extreme drought and limited local food availability.
\end{abstract}

Keywords: Pteropodidae, Epomophorus wahlbergi, bat mating systems, South Africa, figs.

\section{INTRODUCTION}

Sycamore fig trees (Ficus sycomorus) are essential players in many tropical food webs including Kruger National Park (KNP), South Africa. Figs provide an essential biomass of fruits year-round supporting large numbers of primary and secondary consumers, and are especially important during the dry season when little other foods are available to frugivores (Braack 1989, Fenton et al. 1985, Grant et al. 2001, Maclean 1993). Unfortunately, extreme flooding in KNP in 2000 uprooted and killed many mature sycamore fig trees and since then, there has been little evidence of successful germination and recruitment of young trees into these long-standing populations (Naiman et al. 2008). Because of their indispensable importance to sustainability of animal populations in KNP and the grim outlook for population sustainability of sycamore fig trees due to ongoing climate disruption and other contributing factors, it has been estimated that a $66 \%$ reduction in overall biodiversity in the park will occur over the next several decades (Barend et al. 2002).

Wahlberg's epauletted fruit bat, Epomophorus wahlbergi (Chiroptera: Pteropodidae) is a major disperser of sycamore

*Address correspondence to this author at the School of Biological Sciences, Ross Hall, Campus Box 092, University of Northern Colorado, Greeley, CO 80639; Phone: 970.351.2057; Fax: 970.351.2335,

Email; rick.adams@unco.edu fig seeds in KNP and seeds that have passed through its gut have higher germination rates (Bonaccorso et al. 2004, Fenton et al. 1985, Snode 2010). One of the peak breeding seasons for E. wahlbergi coincides with the dry season when $F$. sycomorus provides the major dietary staple for females that are gestating or lactating for young (Monadjem et al. 2010).

A poorly explored facet of the biology of E. wahlbergi regards potential male-male competition for females during the mating season. The mating system of $E$. wahlbergi is organized around multi-male/multi-female groups that mate away from the roost (Bradbury 1977a, b, 1981, McCracken and Wilkinson 2000. Wilkinson 1995) and in the dry season, at least, mating activity is concentrated close to sycamore fig trees having ripe fruits. Thus, sycamore fig trees appear to have a central role in the reproductive biology of epauletted fruit bats, especially during the dry season (Acharya 1992). In addition, the typical local and regional asynchrony in fruiting among sycamore fig trees provides a relatively continuous food supply throughout the dry season breeding cycle (Grant et al. 2001). Intense feeding by bats at night and other animals diurnally results in fig trees typically being exhausted of ripe fruit within 1-4 days, depending on productivity (Kingdon 1974, RA Adams unpublished data).

Male and female E. wahlbergi are sexually dimorphic in both body size (males are larger) and in facial features (males have bulldog-like facial pouches that inflate during mate-calling) (Fig. 1). Males call from perches about 2-3 m 


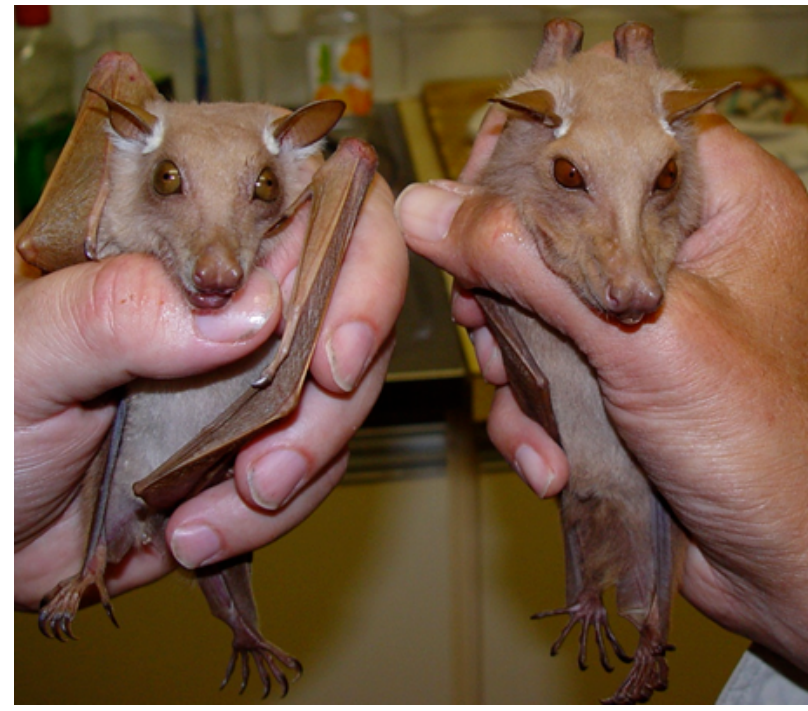

Fig. (1). Photographs of female (left) and male (right) E. wahlbergi illustrating sexual dimorphism of the head and face.

above the ground near, but not within, fruiting fig trees where females are foraging. They display epaulettes located near the shoulder joint and use quick, repetitive wing flaps synchronized around a loud, monotone audible call (Fenton et al. 1985, Wickler and Seibt 1976). In a study concerning multiple calling males at a particular site, Wickler and Seibt (1976) used vocalization intensity (measured in dBs) of recorded calls from a single male taken from different known distances (e.g. $3 \mathrm{~m}$ ) and then extrapolated those data to calculate positional information on three other nearby males calling simultaneously within a forest canopy in Kenya. They found that males positioned themselves at about $50 \mathrm{~m}$ intervals between other calling males, but on one occasion they found the distance between two calling males to be only about $30 \mathrm{~m}$. In addition, they found that solitary males had predictable vocalization patterns whereas males capable of hearing each other altered their calling sequences in an unpredictable manner (Wickler and Seibt 1976). Although very little data exists, mating calls of male $E$. wahlbergi appear to serve two main purposes: 1) to attract females to a mating perch and 2) to enforce dispersion distances among calling males in proximity to fruiting fig trees. It also seems quite plausible that some kind of dominance hierarchy among males could exist, with the more dominant males positing themselves closest to a fruiting fig tree where females are foraging.

One of the major reasons for a lack of information on the mating rituals of epauletted fruit bats is because males are highly sensitive to being approached on foot when calling from a perch and thus fly away before an observer can get within about 10m (Fenton et al. 1985, RA Adams personal observations). In addition, because fruiting fig trees are exhausted so quickly over a few days, there is not time to habituate males to a human presence for direct observation of mating positions among individuals.

In June of 2009 we happened across a unique circumstance wherein we were able to quantify the positions of a relatively large number of calling male epauletted bats along a narrow stretch of riverine corridor that paralleled a road from which we could record mating calls with minimal disturbance to the bats by using our car as a blind. These data provide valuable and unique insights into the dispersion patterns of a large concentration of calling males not before analyzed. In addition, due to drought conditions, our survey of sycamore fig trees in the area revealed that this narrow river corridor $(0.15 \mathrm{~km}$ wide) was the only area where fig trees were fruiting at this time, causing a relatively large number of calling males $(\mathrm{N}=23)$ to congregate around five fruiting fig trees dispersed along a $10 \mathrm{~km}$ section of forest.

Because of what appeared to be an unusually high density of males congregated in a relatively short stretch of river corridor, we hypothesized that the patterns of dispersion among calling males would be clumped, rather than evenly dispersed as reported in the literature and in our previous natural history observation when calling males occur in lower-density.

\section{METHODS}

\section{Study Area}

Kruger National Park is located in north-eastern South Africa encompassing approximately $20,000 \mathrm{~km}$ of diverse landscapes and habitats. The site for this study was located along the Sabie River as it enters the park at its western boundary (Fig. 2), northeast of N'waswitshaca Research Camp near Skukuza. The habitat consisted of thorn thickets with dense bush savanna including red bushwillow, whiteleafed raisin, knob thorn, marula, flaky bark torn, tamboti, magic guarri, horned thorn and scented pod-thorn. Along the Sabie River's edge (as in other major rivers in the Park) sycamore fig trees (Ficus sycomorus) are numerous and produce fruit asynchronously throughout the year providing a significant food resource to wildlife, particularly during the dry season (April - October) when little other food in the form of fruit is available.

\section{Recordings of Male Mating Calls}

On 19 June 2009 we happened upon a high-concentration of calling male $E$. wahlbergi $(\mathrm{N}=23)$. The 23 males were distributed along a $10 \mathrm{~km}$ stretch of a narrow riparian corridor along the Sabie River and as we drove the road we stopped and recorded distance markers using the car's odometer where each male was observed emitting its loudest vocalizations. On the nights of 20 and 21 June 2009, we returned to the river road after devising methods to record the loudest vocalizations of each male from road positions demarcated using both the car's odometer and a Garmin Oregon 550 GPS unit (Olathe, Kansas, USA). We recorded calls of each male using the same Pettersson D240x sonar detector (Pettersson Elektronic, Uppsala, Sweden) attached to a Samson H2 Zoom digital recorder (Samson Technologies, Hauppauge, NY, USA) on each night. As we drove the river road we could hear each consecutively calling male from about $0.5 \mathrm{~km}$ distance. As we slowly approached each calling male with our vehicle, we stopped at a distance before our presence caused any individual to abandon its calling site, but allowed us to clearly record the male's vocalizations. We used a compass in-line with the detector to determine the direction of the calling male from our stationary position. After we had driven the road in a single direction and successfully recorded all calling males, we drove back along the same road in the opposite direction and 

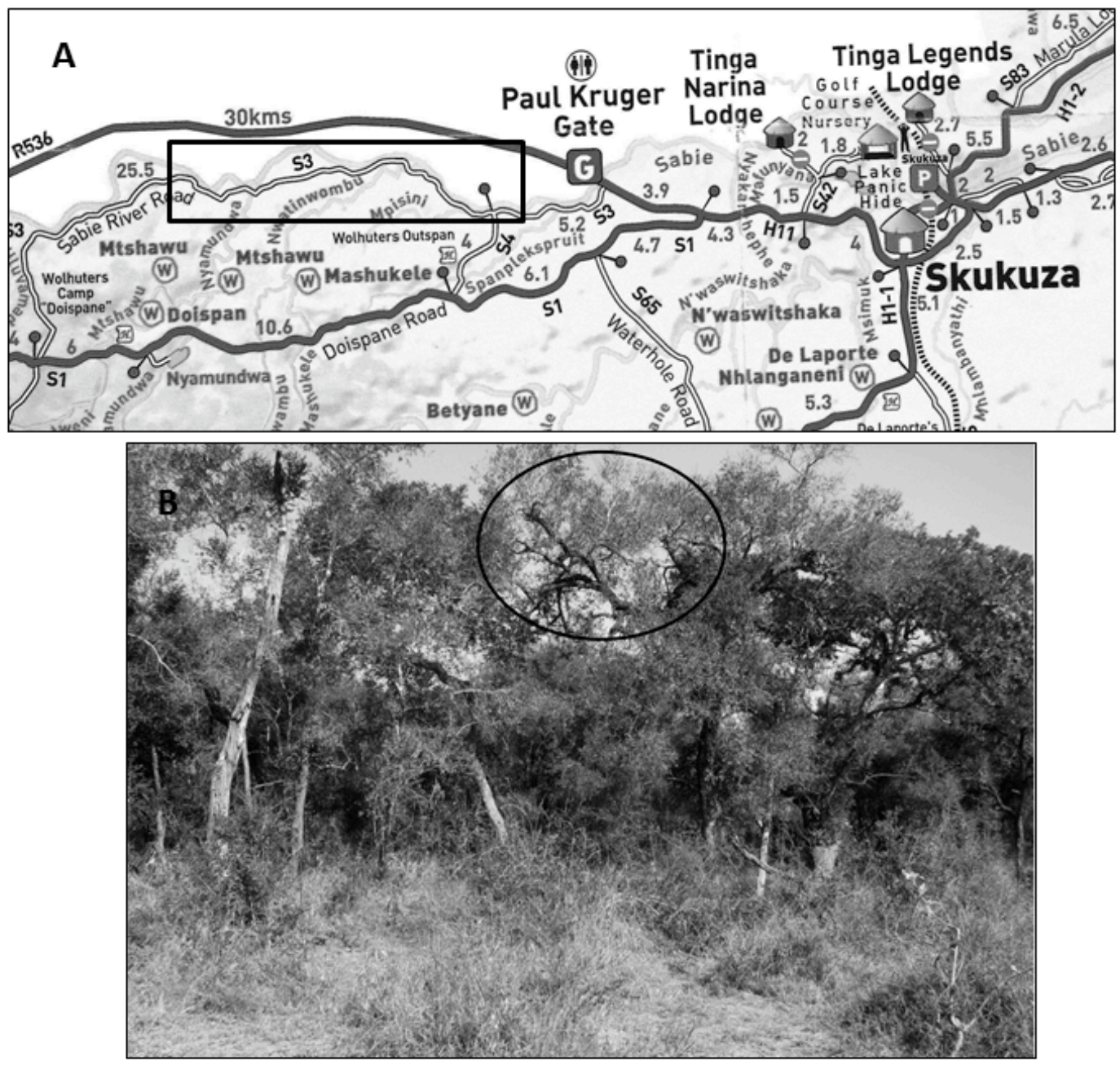

Fig. (2). A. Map of south Kruger National Park. Box illustrates section along the Sabie River where our study took place. B. Photograph representative of habitat within the riverine corridor study site. Circle indicates a sycamore fig tree.

used the odometer and GPS readings to recheck the position of all calling males, thus verifying each individual's position twice per night and corroborating a stationary position for each calling male over the three hours of observations each night. Thus, we are confident that each male was recorded from its primary stationary perch and that we did not inadvertently record any males moving among alternate perches during the observation periods. Because males are known to rotate their head and bodies slowly back and forth during calling bouts (Wickler and Seibt 1976), thereby affecting call intensity in any given direction, we recorded calls from each male until we were confident that we had recorded the loudest vocalization from that individual. On both nights we recorded calls between $2200 \mathrm{~h}$ and $0045 \mathrm{~h}$ with follow-up verification of male positions occurring between 0045 and $0115 \mathrm{~h}$. In addition, we returned during daylight hours with a rangefinder (see below) to assess the positional information of each calling male to be sure that each recorded male was indeed within the river corridor and that there was a tree present at the calculated location for each male.

\section{Determination of Distance Using Vocalization Intensity}

All recorded calls were analyzed with SonoBat 2.8 (Humboldt State University, CA, USA) to calculate basic structural parameter of each male's call and Raven (Cornell University, NY, USA) to determine the relative intensity of each call. We used the inverse square relationship between intensity of sound $(\mathrm{dB})$ and distance (intensity of sound varies inversely with the square of the distance from the source) in combination with our GPS and compass readings to estimate the positional information of each calling male. Thus, if the distance from the sound source is doubled (increased by a factor of 2) the intensity of the vocalization will be quartered (decreased by a factor of 4 ). To calibrate call intensity with distance we used eight recordings taken from a calling male $E$. wahlbergi, that was located in a tree at the edge of the Sabie River where we pulled the vehicle to a position $3 \mathrm{~m}$ away determined by using a Nikon Range Finder (Nikon, Inc., Chicago, IL, USA, error $\pm 0.3 \mathrm{~m}$ ) with the view-finder positioned on the eye shine of the calling individual. We then extrapolated these data to calculate distances of calling males from our positions along the Sabie River road. From our distance and compass data we assigned each calling male a GPS location and derive a 2D map of calling male positions within the forest.

\section{Data Collection on Sycamore Fig Tree Distribution}

We returned to the site during daylight hours to visually locate and map each sycamore fig tree. To do this, we 


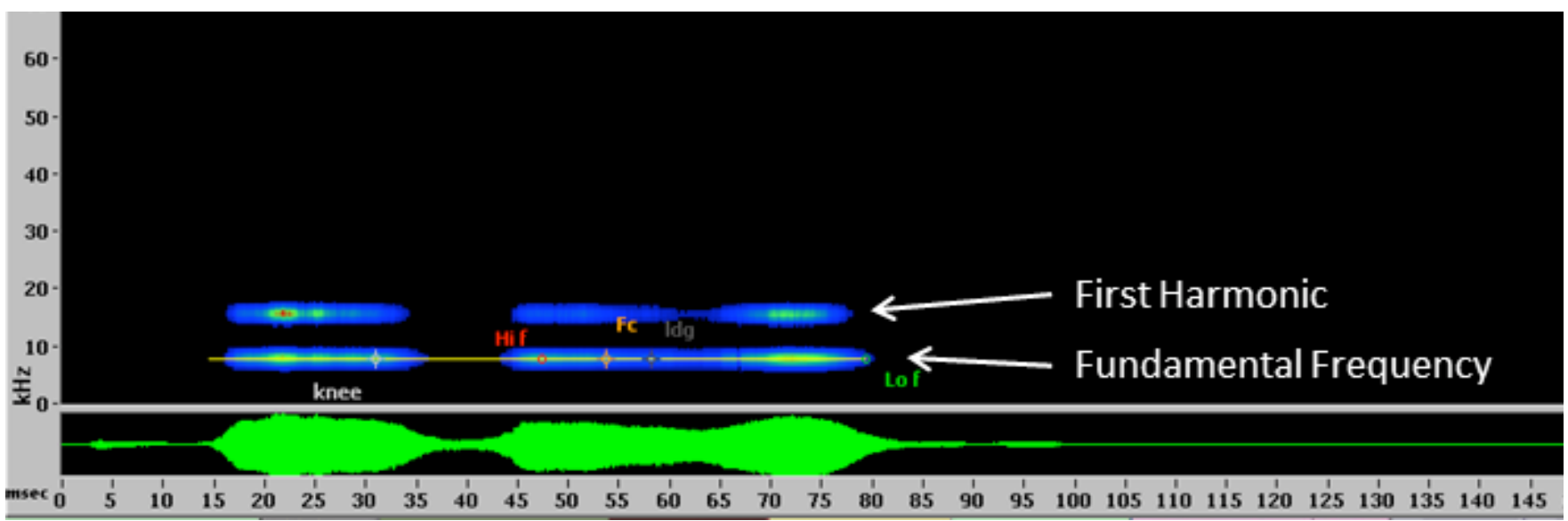

Fig. (3). Representative sonogram profile of a male E. wahlbergi mating call recorded on 21 July 2009.

travelled the river road and used binoculars to locate every fig tree between the north side of the road and the river bed. No fig trees were observed to occur south of the river road. The distance between the road and the near bank of the Sabie River where we surveyed varied, but typically was $<100 \mathrm{~m}$ (Fig. 1) and vegetation density was low enough to allow easy visual observation of fig trees. Once we moved to a position in which a fig tree was in a clear line of sight, we recorded our mileage, the GPS position, and took a compass reading to the fig tree. We then used a Nikon Range Finder (error \pm $0.3 \mathrm{~m}$ ) to determine the distance between us and each fig tree. We also noted which of the fig trees contained ripe fruit verified using binoculars.

\section{Data Analysis}

To test for significant differences between our estimated positional data for each calling male over the two sampling nights, we calculated a UTM index by dividing the northern UTM into the eastern UTM and then ran a linear regression on Night 2 versus Night 1 positional data. In order to determine dispersion among males in the higher- versus lower-density areas, we mapped out in two dimensions the position of each individual using assigned GPS coordinates determined by sound intensity $(\mathrm{dB})$ of the loudest recorded audible mating calls from each male. We then used a metric ruler to measure distances between points plotted on the map $(\mathrm{mm})$ representing each male and its nearest neighbor. If paired individuals were each other's nearest neighbor, then the distance between them was entered twice into the data set (Clark-Evans 1954). We then used the Clark-Evans (1954) nearest neighbor methods to determine dispersion among calling males each night $\left[\mathrm{R}=\overline{\mathrm{r}}_{\mathrm{A}} \overline{\mathrm{r}}_{\mathrm{E}}\right.$ wherein $\overline{\mathrm{r}}_{\mathrm{A}}$ (mean of observed distances to nearest neighbor) $=\sum \mathrm{r}$ (distance to nearest neighbor) $/ \mathrm{N}$ and $\overline{\mathrm{r}}_{\mathrm{E}}$ (mean expected) $=1 / 0.5 \sqrt{ } \rho$ wherein $\rho=$ density (number of individuals per unit area)]. If $\mathrm{R}=1$, the dispersion is random, $\mathrm{R}>1$ describes uniform dispersion, and $\mathrm{R}<1$ describes clumped dispersion. We compared our data to a normalized curve to test for significance of $\mathrm{R}$ using the formula $\mathrm{c}={ }^{-} \mathrm{r}_{\mathrm{A}}-{ }^{-} \mathrm{r}_{\mathrm{E}} / \sigma_{-}{ }^{-} \mathrm{r}_{\mathrm{E}}$ wherein $\sigma$ is the standard error is the standard error of the mean distance to nearest neighbor in a randomly distributed population of the same density as that of the observed population. We also measured distances between all males to test (t-test) for significant differences in distance between males in areas of higher and lower density (i.e. number of males per $\mathrm{km}$ ).

\section{RESULTS}

\section{Fruiting Sycamore Fig Trees}

Ficus sycomorus trees are known to fruit asynchronously throughout KNP (Bonacorrso et al. 2004) thereby providing fruits throughout the dry season. In our experience over three years of surveys during the same months (late May to early July) of the dry season, it was relatively rare to find five sycamore fig trees fruiting in such proximity to one another. Our survey of fig trees in 2009 (Snode 2010) located and tracked in KNP by Bonacorrso et al. (2004) in previous years indicated these were the only fruiting figs in the area within approximately $200 \mathrm{~km}$ of Skukuza.

\section{Description of Male Mating Call}

The highest intensity of eight calls recorded from a male E. wahlbergi from a distance of $3 \mathrm{~m}$ was $97.1 \mathrm{~dB}$ (range of recording 85.4-97.1 dB) and we used this call intensity to calibrate locations and distances among all other male $E$ wahlbergi calling along the Sabie River. Wickler and Seibt (1976) measured highest intensity calls from a male $E$. wahlbergi in Kenya from a distance of $3 \mathrm{~m}$ to be $70-72 \mathrm{~dB}$ that they used in similar calculations. The males we recorded from this site on both nights (recording Night $1=17$, recording Night $2=19$ ) produced audible, relatively constant frequency calls $49.92-84.31 \mathrm{~ms}$ in duration with highest fundamental frequencies between $7.80-7.93 \mathrm{kHz}$ and ending at slightly lower frequencies between $7.63-7.79 \mathrm{kHz}$ (range of total slopes $=0.0012-0.0015)$ (Fig. 3). A second harmonic was typical at about $15-16 \mathrm{KHz}$.

\section{Number of Calling Males and Consistency of Positional Calculations}

The number of males calling on any given night varied [Night $0=23$ (no recordings), Night $1=17$, Night $2=19$ ] however, over the three nights of observation the locations of calling males as determined by road kilometer distances seemed highly consistent. A linear regression run on UTMs indices representing positional data estimated for 17 males calling on both nights was highly significant $\left(\mathrm{R}^{2}=0.96, \mathrm{R}=\right.$ $0.98, \mathrm{P}=0.0001)$ thus showing high correlation in positional 


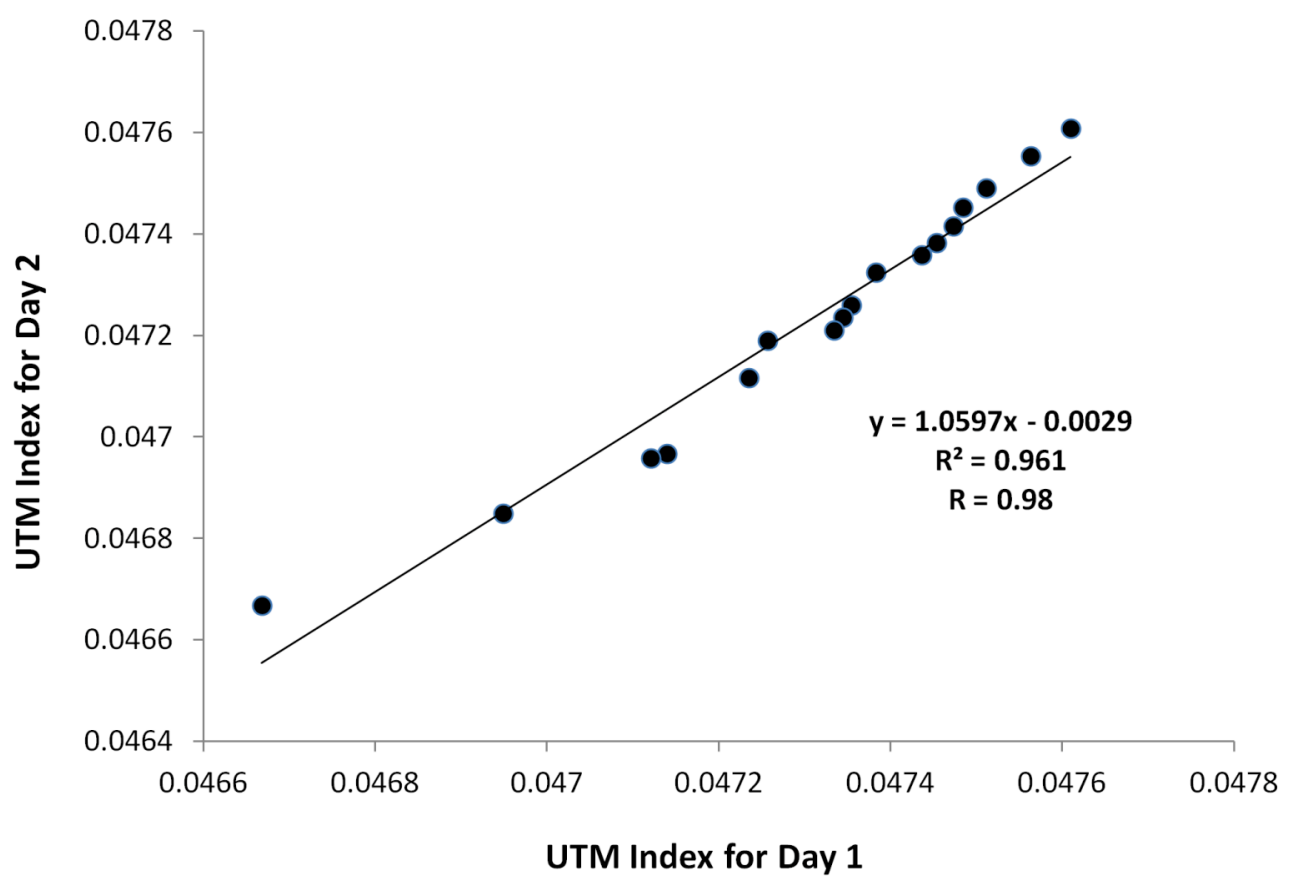

Fig. (4). Linear regression plot of UTM indices calculated for each night's positional calculations against each other. Estimated perch locations for calling males was strongly correlated across nights $(\mathrm{R}=0.98)$.

estimates for calling males across nights (Fig. 4). Our diurnal survey of the area found that in all cases a tree was positioned at the sound-estimated distance and position of each calling male and there were no erroneous data points that fell outside of $0.15 \mathrm{~km}$ wide river corridor between the road and the near bank of the Sabie River. Thus, our calculations appear to be accurate in determining the positions of each calling male.

\section{Dispersion Among Calling Males}

Using a Clark-Evans (1954) nearest neighbor analysis of data gathered on Night 1 , we determined that individuals were $25 \%$ more clumped than randomly dispersed $(\mathrm{R}=$ 0.75). Curiously, on Night 2 when 19 males were calling, nearest neighbor analysis determined that individuals were even more tightly clumped $(\mathrm{R}=0.58)$. Test for significance of $\mathrm{R}$ based on the normal curve showed significant differences from random dispersion on both nights (Night 1 $(\mathrm{N}=17), \mathrm{C}=5.75, \mathrm{P}<0.001$; Night $2(\mathrm{~N}=19), \mathrm{C}=7.66, \mathrm{P}$ $<0.001)$.

In addition, we found that some, but not all, calling males positioned themselves near five sycamore fig trees having ripe fruit out of a total of 16 fig trees within the study area. Our calculations indicate that males were calling from perches in trees proximate to, but not within, ripe fig trees. Positional information indicated that there were usually differential distances among males in proximity to a particular rip fig tree with one of the males being positioned nearest the tree and the others at varying distances away. (Fig. 5).

We determined that along the $10 \mathrm{~km}$ corridor there were higher-density (11 males along a $\sim 2 \mathrm{~km}$ stretch of river corridor) and lower-density ( 8 males along $\sim 8 \mathrm{~km}$ of river corridor) areas of calling males. The next day we observed that the lower-density area was in proximity to fig trees with lower fruit abundance and the distance between the calling male most proximate to a fruiting fig tree and its nearest calling neighbor was $150 \mathrm{~m}$, whereas in the higher-density area, the nearest neighbor of the male most proximate to a fruiting tree was only $25 \mathrm{~m}$ and these differences were significant. In addition, there was significantly shorter distances among all males perched in the higher-density area when compared to distances among males in the lowerdensity area (higher-density area mean $=67.5 \mathrm{~m}, S D=$ $42.0 \mathrm{~m}$, lower-density area mean $=284.5 \mathrm{~m}, S D=188 \mathrm{~m}, T=$ $3.59, D F=15,=P<0.001)$.

\section{DISCUSSION}

In this study we were able to show an accurate and novel depiction of how a large aggregation of male E. wahlbergi disperse themselves among a groups of fruiting fig trees in Kruger National Park during the dry season in a drought year (2009). We found that the number of males calling varied each night $(N=23,17,19$ respectively), but that males did not maintain an equidistance of $50 \mathrm{~m}$ from other calling males as described by Wickler and Seibt (1976), but instead exhibited tighter clumpness among individuals in areas of higher density and greater fig abundance. The relationship between calling males and the most proximate ripe fig tree showed that the shortest distance between a male in closest proximity of a fruiting fig tree and its next nearest-neighbor calling male was only $25 \mathrm{~m}$ in the high-density area, but extended to $150 \mathrm{~m}$ in the lower-density area. Although far from conclusive, the distributional pattern of males (i.e. that not all calling males were as close to ripe fig trees as possible, but rather that males were stationed in a staggered pattern with increasing distance from foraging females) may indicate a dominance hierarchy among males with the most dominant individuals nearest a ripe fig tree and thus more likely to be noticed by a foraging female. This pattern did not differ between higher- and lower-density areas. 
A

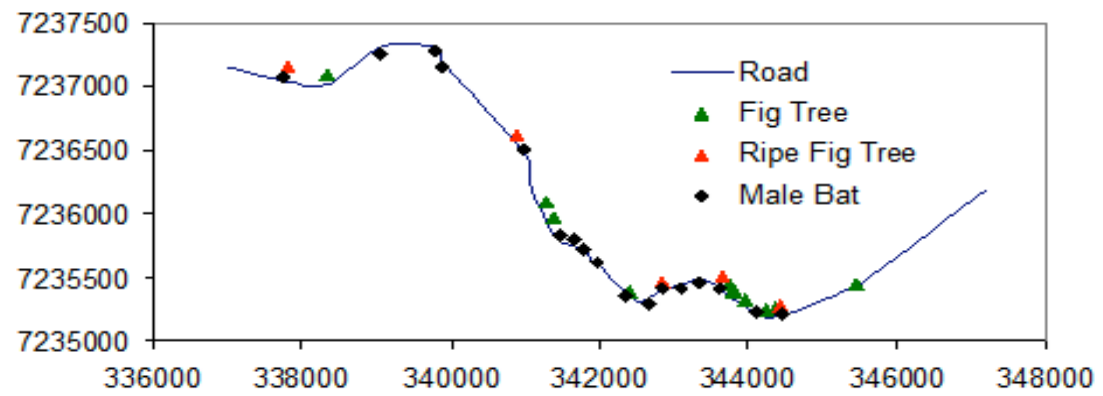

B
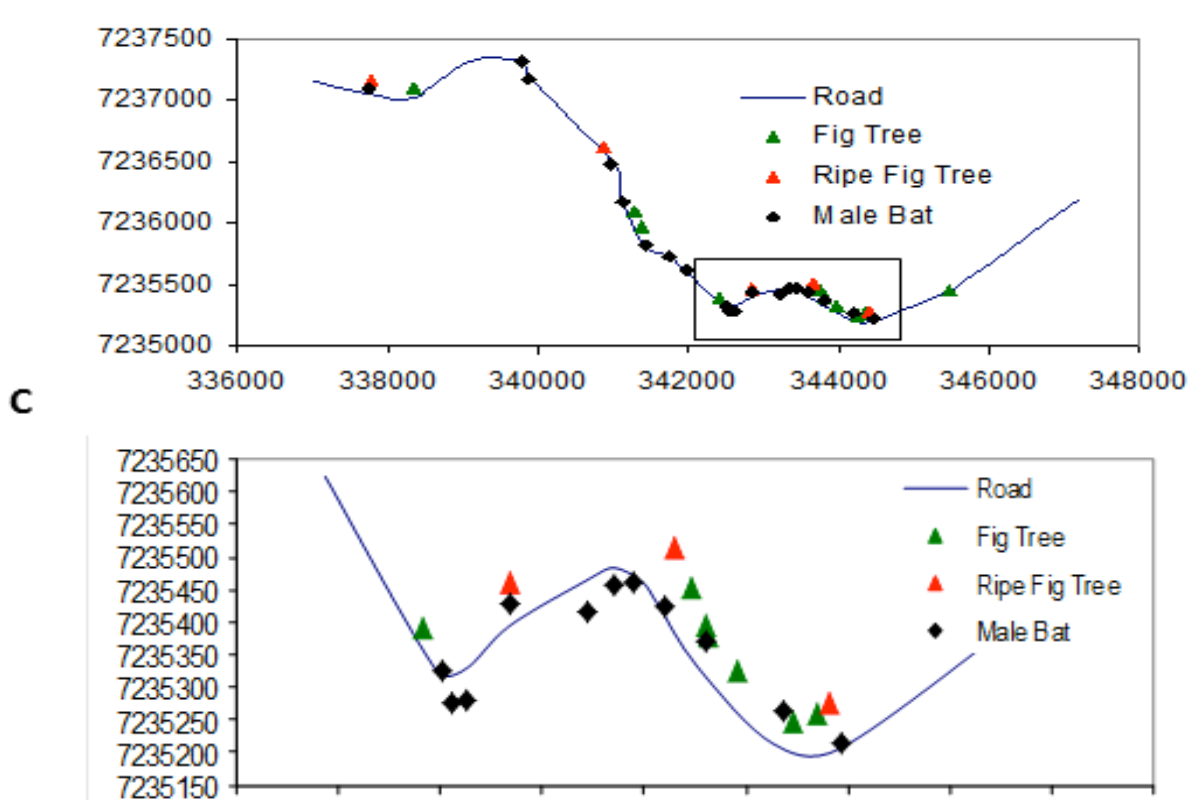

341500342000342500343000343500344000344500345000345500346000

Fig. (5) Maps illustrating dispersion of calling male E. wahlbergi based upon UTM points and compass readings from stationary recording locations along the Sabie River road as calculated by using call intensity (x-axis $=$ easting, $y$-axis $=$ northing). Night 1 positions of calling males, $\mathrm{N}=17)(\mathbf{A})$. Night 2 calling males $(\mathrm{N}=19)$. Box indicates area of highest number of calling males $(\mathbf{B})$. Night 2 zoomed-in area of higher-density of calling males indicated by box in B $(\mathbf{C})$.

The reduction in dispersion among males in the higherdensity area suggests the potential of more intense mating competition among males for females when many males are vying for attention. Calling males that roosted farther from ripe fig trees were typically located near nonfruiting fig trees. Fenton et al. (1985) found that male E. wahlbergi roosted in sycamore fig trees lacking fruit during the day. However, we did not find males calling from nonfruiting sycamore fig trees at night.

We have also observed that when sycamore fig trees were ripe with fruit in other parts of KNP that both males and females would commute a short distance of several meters after securing a fig to a proximate tree where it consumed the fruit. It is possible that males position themselves along these flight corridors between foraging and feeding trees. Although we were not able to observe directly any behaviors of individuals during this study except the male we recorded the vocalization from to standardize distance and decibel level, we did hear what appeared to be females emitting soft, but audible vocalizations in proximity to some of the calling males who would increase their call rates in apparent response, similar to that observed by Wickler and Seibt (1976).
Although we realize that strong conclusion cannot be drawn from a three night study, we do provide some important insight into male epaulleted fruit bat biology that can be used to better understand the relationship among calling males and fruiting sycamore fig trees. Because of the sensitivity of calling males to approach on foot (Fenton et al. 1985, RA Adams and ER Snode personal observations) and high consumption rates of ripe figs by fruit bats and other wildlife, there is typically not enough time to habituate males to approaches on foot in order to observe mating behaviors. For example, it took Fenton et al. (1985) one week to reduce from $10 \mathrm{~m}$ to $5 \mathrm{~m}$ their approach distance on foot to diurnally roosting E. wahlbergi. Although there is some indeterminate error in using sound to estimate distance between two points, we strove to verify our estimates by corroborating independent data from repeated measures of calling male positions on each night as well as across nights and diurnal distance measurements using a range-finder with compass to verify that male calling perches were within the corridor and in positions of potential calling trees. We feel that the value of this study supersedes any small inaccuracies that may have been accrued during our observations. 
Because Old World fruit bats exist at much lower population densities than do New World fruit bats, their effect on ecosystems tends to be larger than their biomass and therefore slight decreases in population numbers may have large ecological effects, particularly for canopy trees such as sycamore figs (Muscarella and Fleming 2007). Understanding the mating dynamics of epauletted fruit bats in relation to food resources is important in light of expected changes in food availability in South Africa due to climate change-induced temperature increases and drought. It is apparent that reductions in the number of mature sycamore trees in KNP will have dramatic effects on populations of epauletted fruits bats and other animals during the dry season which is one of the two reproductive periods for $E$. wahlbergi and thus females may not have the food availability required to complete gestation or lactation. In addition, reduced fruiting may increase competition for mates among male epauletted fruit bats, thereby increasing the energetic demands of reproduction and thus potentially lowering survivorship.

\section{CONFLICT OF INTEREST}

The authors confirm that this article has no conflict of interest.

\section{ACKNOWLEDGEMENTS}

We would like to thank Kruger National Park (KNP) for allowing us to conduct research and to Scientific Services of KNP for providing game guards for our protection. We also acknowledge the University of Northern Colorado for providing monetary support for this research. We thank John Winkelmann for use of his Nikon Range Finder.

\section{REFERENCES}

Acharya, L (1992) Epomophorus wahlbergi. Mammalian Species, 394.

Barend, FN, Van Jaarsveld, AS, Chown, SL, Kshatriya, M \& Wessels, KJ (2002) Vulnerability of South African animal taxa to climate change. Global Change Biology, 8, 679-93.

Bonaccorso, F, Winklemann, J, Deacon, A \& MacFadyen, S (2004). On the distribution of Ficus sycomorus and movements of Epomophorus fruit bats in Kruger National Park, South Africa. Bat Research News, 45, 205-06.

Braack, LEO (1989) Arthropod inhabitants of a tropical cave 'island' environment provisioned by bats. Biological Conservation, 84, 7784.

Bradbury, JW (1977a) Social organization and communication. In: Wimsatt, WA (Ed) Biology of Bats, New York, Academic Press pp. 1-73.

Bradbury, JW (1977b) Lek mating behavior in the hammer-headed bat. Zeitschrift für Tierpsychologie, 45, 225-55.

Bradbury, JW (1981) The evolution of leks. In: Alexander, RD \& Tinkle, DW (Eds) Natural Selection and Social Behavior, New York, Chiron Press pp. 138-73.

Clark, P \& Evans, F (1954). Distance to nearest neighbor as a measure of spatial relationships in populations. Ecology, 35, 445-53.

Fenton, BB, Brigham, RM, Mills, AM \& Rautenbach, IL (1985) The roosting and foraging areas of Epomophorus wahlbergi (Pteropodidae) and Scotopholis viridis (Vespertilionidae) in Kruger National Park, South Africa. Journal of Mammalogy, 66, 461-68.

Grant, R, Thomas, V, \& Van Gogh, J (2001) Sappi Tree Spotting: Lowveld including Kruger National Park, $2^{\text {nd }}$ ed, Jacana Press, Johannesburg. Kingdon, J (1974) East African Mammals, vol 2, Insectivores and Bats. Academic Press, New York.

Kingdon, D (1974) East African Mammals: An atlas of Evolution in Africa. Insectivores and Bats. Academic Press, New York.

Maclean, GL (1993) Roberts' Birds of Southern Africa, John Voelcker Bird Book Fund, Cape Town.

McCracken, GF \& Wilkinson, GS (2000) Bat mating systems. In: Chrichton EG \& Krutzsch, PH (Eds) Reproductive Biology of Bats, New York, Academic Press 321-62

Monadjem, A, Taylor PJ, Cotterill, FPD \& Schoeman, MC (2010) Bats of Southern and Central Africa, Wits University Press, Johannesburg.

Muscarella, R \& Fleming, TH (2007) The role of fruigivorous bats in tropical forest succession. Biological Review, 82, 573-90.

Naiman, RJ, Latterell, JJ, Pettit, NE \& Olden, JD (2008) Flow variability and the biophysical vitality of river systems. Geoscience, 340, 62943.

Snode, E (2010) Effects of Epauletted Fruit Bats (Epomophorus crypturus and Epomophorus wahlbergi) on the Seed Germination of Sycamore Fig Trees (Ficus sycomorus) in Kruger National Park, South Africa. Unpublished MS Thesis, University of Northern Colorado, Greeley, USA.

Wickler, W \& Seibt, U (1976) Field studies on the African fruit bat, Epomophorus wahlbergi (Sundevall), with special reference to male calling. Zeitschrift für Tierpsychologie, 45, 225-55.

Wilkinson, GL (1995) Information transfer in bats. In: Racey PA \& Swift SM (Eds) Ecology, Evolution and Behaviour of Bats. Oxford, Oxford University Press pp. 345-60.

(C) Adams and Snode; Licensee Bentham Open.

This is an open access article licensed under the terms of the Creative Commons Attribution Non-Commercial License (http://creativecommons.org/ licenses/by-nc/3.0/), which permits unrestricted, non-commercial use, distribution and reproduction in any medium, provided the work is properly cited. 